\title{
Espaço olhar digital
}

Recebido em 29.04.2015. Aprovado em 05.05. 2015 Avaliado pelo sistema double blind review

\author{
Graziela da Silva Moreira \\ ceprofessorclovismonteiro@educacao.rj.gov.br \\ Colégio Estadual Professor Clóvis Monteiro- Higienópolis-RJ - Brasil.
}

\section{Resumo}

As mídias podem trazer à tona as novas linguagens comunicacionais, que são importantes para as novas formas de ensinar e aprender, tornando os sujeitos participantes desta sociedade globalizada. É a partir da aquisição das informações e dos conhecimentos que os indivíduos têm uma visão de mundo diferenciado, pois na medida em que se adquirem novos conhecimentos também se tornam diferentes. A realidade escolar aos poucos vem mudando e modernizando a exemplo das possibilidades de uso das mídias como, a TV, vídeo, DVD, projetor multimídia, internet.

Através da ação "Resgatando IF" realizada pela Equipe Pedagógica, na qual o objetivo foi conscientizar os alunos com baixo rendimento e diagnosticar as dificuldades no processo ensino-aprendizagem, a escola identificou um jovem que já repetiu 0 ano duas vezes e reclamou da qualidade das aulas e da forma de avaliação. Assim, ficou claro que a escola precisa se aproximar da realidade dos alunos, entender as suas expectativas e anseios e envolvê-los de forma a adequar melhor a Proposta Pedagógica às necessidades, aprimorando o ensino e torná-lo mais atrativo. Vários alunos usam celulares e tem acesso à internet, utilizando a rede para acompanhar as novidades sobre tecnologia e entrar nas redes sociais. É necessário melhorar a infraestrutura, fornecendo ao professor e a prática pedagógica suporte tecnológico.

Assim, o Projeto Espaço Olhar Digital visa implantar salas de mídia na escola e adaptar espaços, e tem como objetivo dinamizar a prática pedagógica adequá-la às necessidades da clientela e tornar as aulas mais atrativas recheadas de fóruns, apresentações, seminários, discussões em sala de aula e trabalhos em grupo. É importante ressaltar que a escola ganhou projetos e programas que valorizam o uso das tecnologias, como a modalidade de ensino NEJA e o Reforço Escolar, nos quais existe formação específica. Ao final das ações, a escola promoverá uma Feira Tecnológica, que será a culminância dos trabalhos realizados.

Será necessário um empreendimento de recursos tecnológicos, como computadores, data show, lousa digital, TV, DVD, Wifi, quadro branco escolar, armários e reforma da estrutura das salas como fiação, pintura e climatização.

Palavras-chaves: Educação. Práticas pedagógicas. Plano de empreendimento. Salas de mídia. 


\section{Caracterização da escola}

O Colégio Estadual Professor Clóvis Monteiro foi fundado em1951 e está localizado em Higienópolis / Rio de Janeiro. A Escola atende a 1.373 alunos, distribuídos nas séries atendidas, $1^{\circ}, 2^{\circ}$ e $3^{\circ}$ ano do Ensino Médio e NEJA.

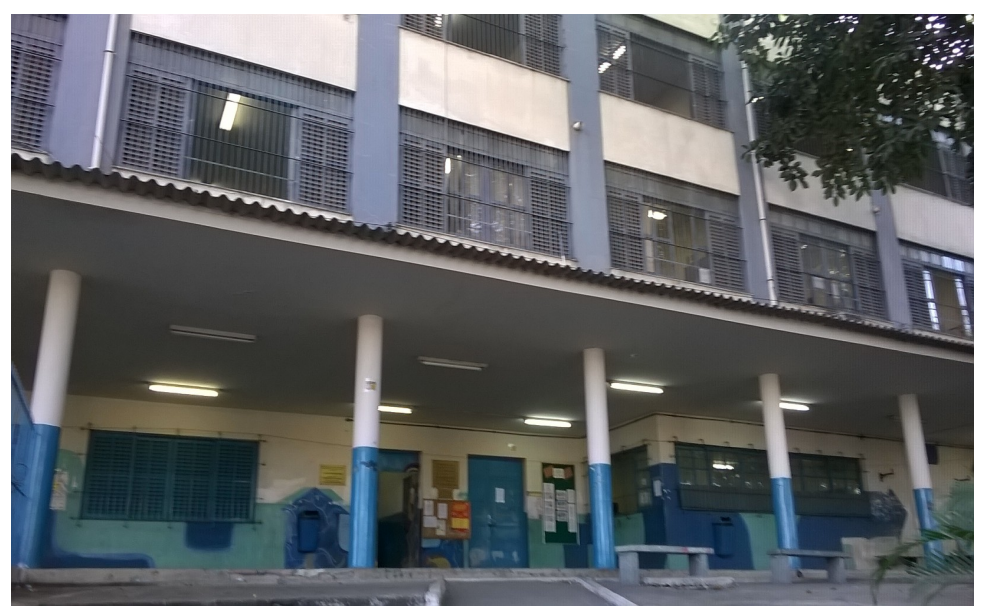

\section{Missão:}

Contribuir para o desenvolvimento do aluno, em todas as suas potencialidades, no que tange 0 aspecto profissional, cultural, a fim de garantir o uso pleno de sua cidadania.

Trazer a responsabilidade da Comunidade escolar em torno de uma prática de cogestão, a fim de estabelecer uma relação prazerosa e solidária no trabalho, para melhorar a qualidade do ensino-aprendizagem.

\section{Visão:}

Ser reconhecida regionalmente como uma escola pública de referência, através do trabalho de construção de conhecimentos, contribuindo para o crescimento social da comunidade escolar e local visando participação ativa da sociedade, no processo de ensino aprendizagem; além do objetivo de ser referência em qualidade de ensino até dezembro de 2014.

\section{Instalações}

A unidade escolar tem estrutura antiga, com data de fundação de 1951. Até então, não passou por reformas significativas, possuindo 0 aspecto antigo. Existem algumas instalações desativadas que dependem de obras que são de responsabilidade da Secretaria de Educação, pois deve haver um parecer técnico. Porém, as possibilidades de pequenas reformas em algumas instalações são viáveis. É importante ressaltar que 0 diagnóstico da estrutura, no que tange à responsabilidade da Secretaria, é informado constantemente à Regional. E que a gestão atual, ao assumir no meado de 2013, encontrou a escola em condições desfavoráveis na estrutura e na parte financeira, pois a unidade sofreu um embargo fiscal da Receita Federal, gerado pela prestação de contas inconsistente da gestão anterior.

A escola possui 16 salas de aula, onde funcionam os 3 turnos, 1 biblioteca, 1 laboratório de Ciências (no momento desativado), 1 laboratório de informática, 1 quadra esportiva (sendo 1 desativada), 1 refeitório, 1 sala de artes, 1 sala de rádio escolar, 3 salas de núcleo de cultura, 1 secretaria, 1 guarita, 1 sala de Professores, 1 sala de Coordenação Pedagógica, 1 sala da Orientação Educacional, 1 sala de Direção, 1 sala de vídeo (onde funciona o Reforço Escolar). 


\section{Breve histórico}

O quadro a seguir apresenta a relação dos acontecimentos mais relevantes para a evolução da escola, desde a fundação até hoje.

\begin{tabular}{|c|c|}
\hline Ano & Acontecimentos relevantes \\
\hline 1951 & Fundação da escola \\
\hline 2010 & Realização do Curso de TIC (Intel/Fundação Bradesco) Informática Educativa \\
\hline 2011 & Reforma e Troca de Pintura do Colégio \\
\hline 2013 & Mudança da Gestão do Colégio \\
\hline 2014 & Implementação de Ações Pedagógicas e Parcerias \\
\hline
\end{tabular}

\section{Professores e funcionários}

A equipe é formada por 97 professores, distribuídos da seguinte forma:

\begin{tabular}{|c|c|}
\hline Disciplina / Área & Quant. de professores \\
\hline Biologia & 5 \\
\hline Matemática & 16 \\
\hline L. Portuguesa & 12 \\
\hline Química & 7 \\
\hline Física & 6 \\
\hline Geografia & 5 \\
\hline História & 9 \\
\hline Filosofia & 6 \\
\hline Sociologia & 5 \\
\hline Artes & 3 \\
\hline L. Estrangeira & 10 \\
\hline Educação Física & 6 \\
\hline
\end{tabular}

Do total de professores, 90 são efetivos, 7 readaptados, 64 professores têm Pós-Graduação, 10 possuem Mestrado e 2 Doutorado. Além disso, a escola conta com 7 auxiliares de serviços gerais, 6 de manipuladoras de alimentos, 2 porteiros.

\section{Perfil dos alunos}

Os alunos estão distribuídos por séries e turnos da seguinte maneira:

\begin{tabular}{|c|c|c|c|c|c|c|c|c|}
\hline \multirow[b]{2}{*}{ Série/Ano } & \multirow{2}{*}{$\begin{array}{c}\text { Média } \\
\text { de } \\
\text { idade }\end{array}$} & \multirow[b]{2}{*}{$\begin{array}{l}\text { Total de } \\
\text { alunos }\end{array}$} & \multicolumn{2}{|c|}{ Manhã } & \multicolumn{2}{|c|}{ Tarde } & \multicolumn{2}{|c|}{ Noite } \\
\hline & & & $\begin{array}{c}\mathrm{N}^{\circ} \\
\text { alunos }\end{array}$ & $\begin{array}{c}\mathrm{N}^{0} \\
\text { turmas }\end{array}$ & $\begin{array}{c}\mathrm{N}^{\circ} \\
\text { alunos }\end{array}$ & $\begin{array}{c}\mathrm{N}^{\circ} \\
\text { turmas }\end{array}$ & $\begin{array}{c}\mathrm{N}^{\circ} \\
\text { alunos }\end{array}$ & $\begin{array}{c}\mathrm{N}^{0} \\
\text { turmas }\end{array}$ \\
\hline $1^{\circ}$ E.M. & $15 / 16$ & 512 & ${ }^{*}$ & ${ }^{*}$ & 397 & 16 & 115 & 3 \\
\hline $2^{\circ}$ E.M. & 17 & 385 & 278 & 8 & ${ }^{*}$ & ${ }^{*}$ & 107 & 3 \\
\hline $3^{\circ}$ E.M. & $17 / 18$ & 187 & 137 & 4 & ${ }^{*}$ & * & 50 & 1 \\
\hline NEJA I & $\begin{array}{l}\text { Acima } \\
\text { de } 18\end{array}$ & 22 & * & * & * & * & 22 & 1 \\
\hline NEJA II & $\begin{array}{l}\text { Acima } \\
\text { de } 18\end{array}$ & 35 & * & * & * & * & 35 & 1 \\
\hline NEJA III & $\begin{array}{l}\text { Acima } \\
\text { de } 18\end{array}$ & 38 & * & * & * & * & 38 & 1 \\
\hline NEJA IV & $\begin{array}{l}\text { Acima } \\
\text { de } 18\end{array}$ & 31 & * & * & * & * & 31 & 1 \\
\hline TOTAL & - & 1210 & 415 & 12 & 397 & 16 & 398 & 11 \\
\hline
\end{tabular}

Os alunos realizam as atividades da escola, dentre elas as Avaliações Externas como o Saerjinho, que apresenta um bom índice de participação, as Oficinas das Artes (Grafite, Teatro, Dança de Salão e Música), e as atividades com parcerias como a Oficina Rádio Escola "Nas Ondas do Ambiente" e Projeto PROVOC 
(FIOCRUZ). Existem muitos alunos inseridos no mercado de trabalho e que realizam estágios. 0 comportamento e a disciplina podem ser classificados no nível regular, qualquer situação é tratada juntamente com a Orientação Educacional. Do corpo, $50 \%$ moram próximo à escola e $50 \%$ em outros bairros e comunidades próximas. O envolvimento das famílias ainda não é o suficiente e reflete no índice de fluxo da escola (evasão/ aprovação e retenção). Existem dificuldades no contato com os responsáveis.

\section{Características do entorno}

É localizada na Zona Norte da cidade. Atualmente, apenas a localidade junto à Estação Ferroviária de Manguinhos atende pelo nome de Manguinhos, sendo as demais áreas do bairro conhecidas por nomes das favelas que o caracterizam: "Coreia", "Mandela" e "Amorim". Desde a década de 1980, a área vem sofrendo com o esvaziamento econômico, uma vez que as poucas indústrias que existiam em seu entorno foram extintas. A Refinaria de Manguinhos ainda é a principal instalação industrial da região. Sendo praticamente tomado por favelas, o bairro foi palco de inúmeros confrontos armados entre policiais e traficantes de drogas ou entre quadrilhas de traficantes rivais, até a Pacificação (implementação da $29^{\circ}$ UPP e a inauguração da Cidade da Polícia em 2013). A Rua Leopoldo Bulhões, uma das principais do bairro, que tangencia a linha do trem (Ramal Central - Gramacho), foi conhecida como "Faixa de Gaza", em referência à região homônima na Palestina, famosa pela violência.

Hoje, com a Pacificação, percebe-se um nível de normalidade/segurança no bairro, o que facilitou a interação da escola com o comércio local (utilização pelos funcionários, como farmácia, mercado, lava-jato e até salão de beleza) e as parcerias como a FIOCRUZ (Projeto PROVOC: iniciação científica) e o próprio Batalhão Militar (Ronda Escolar) do Entorno. Além disso, a escola conta com o PROEIS (2 policiais por dia na escola), que tem a parceria da SEEDUC com a Polícia Militar do Rio de Janeiro. Além desses atores, temos também funcionários administrativos que residem na comunidade, mantendo um elo de ligação da comunidade com a escola.

Esses itens pontuais colaboram a cada dia com a unidade escolar, no sentido de divulgação das ações da unidade, segurança, interação, etc. Dessa forma, têm contribuindo cada vez mais para os bons resultados da escola ultimamente, como na avaliação externa do SAERJ.

Identificação do problema e da oportunidade

\section{IDERJ}

\section{Resultado IDERJ para o $3^{\circ}$ ano do E. Médio}

\begin{tabular}{|c|c|c|c|c|}
\hline ANO & $\mathbf{2 0 1 2}$ & $\mathbf{2 0 1 3}$ & $\mathbf{2 0 1 4}$ & $\mathbf{2 0 1 5}$ \\
\hline Metas projetadas & 2,1 & 2,6 & 3,3 & 4,0 \\
\hline IDERJ observado & 1,0 & 1,2 & - & - \\
\hline
\end{tabular}

Fonte: GIDE 


\section{Avaliação Estadual / SAERJ}

Língua portuguesa

\begin{tabular}{|c|c|}
\hline PERCENTUAL & NÍVEL DE PROFICIÊNCIA \\
\hline 35,8 & BAIXO \\
\hline 43,0 & INTERMEDIÁRIO \\
\hline 19,9 & ADEQUADO \\
\hline 1,3 & AVANÇADO \\
\hline
\end{tabular}

\section{Matemática}

\begin{tabular}{|c|c|}
\hline PERCENTUAL & NIVEL DE PROFICIÊNCIA \\
\hline 72,8 & BAIXO \\
\hline 26,5 & INTERMEDIÁRIO \\
\hline 0,7 & ADEQUADO \\
\hline 0 & AVANÇADO \\
\hline
\end{tabular}

Avaliações e relatórios internos

\begin{tabular}{|c|c|c|c|c|c|c|c|}
\hline Série/Ano & $\begin{array}{c}\text { Matrícula } \\
\text { Inicial }\end{array}$ & $\begin{array}{c}\text { Aprovados } \\
\text { S/dep. }\end{array}$ & Reprovados & $\begin{array}{c}\text { Aprovados c/ } \\
\text { dep. }\end{array}$ & Transferidos & Evasão & $\begin{array}{c}\text { Aprovados c/ } \\
\text { dep. }\end{array}$ \\
\hline $1^{\mathbf{a}}$ & 938 & 231 & 201 & 120 & 100 & 253 & 838 \\
\hline $2^{\text {a }}$ & 350 & 131 & 60 & 56 & 19 & 84 & 331 \\
\hline $3^{\mathbf{a}}$ & 246 & 129 & 8 & 38 & 19 & 52 & 227 \\
\hline
\end{tabular}

Foi realizada uma pesquisa de campo com alunos do turno da manhã e tarde, através da ação "Resgatando IF", relatando a porcentagem referente à avaliação dos itens, com os seguintes resultados: 


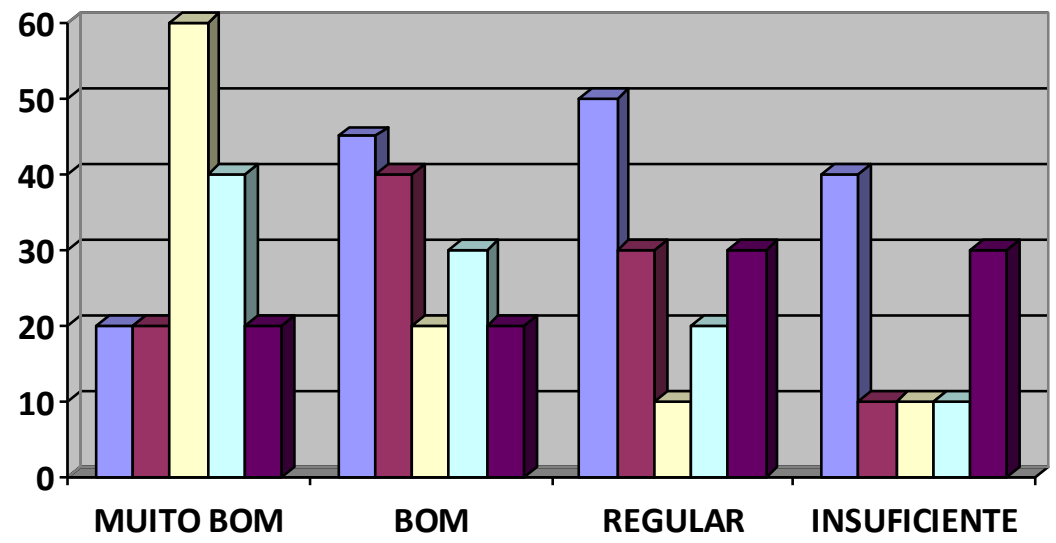

\begin{tabular}{|l|}
\hline$\square$ AULAS \\
$\square$ PROFESSORES \\
$\square$ BIBLIOTECA \\
$\square$ RECURSOS \\
$\square$ MÍDIAS \\
\hline
\end{tabular}

Segundo os professores, os principais problemas que têm impactado diretamente na aprendizagem são evasão, desinteresse, distorção idade-série, alunos oriundos de projetos de aceleração, falta de acompanhamento da família..., relatados no seguinte gráfico:
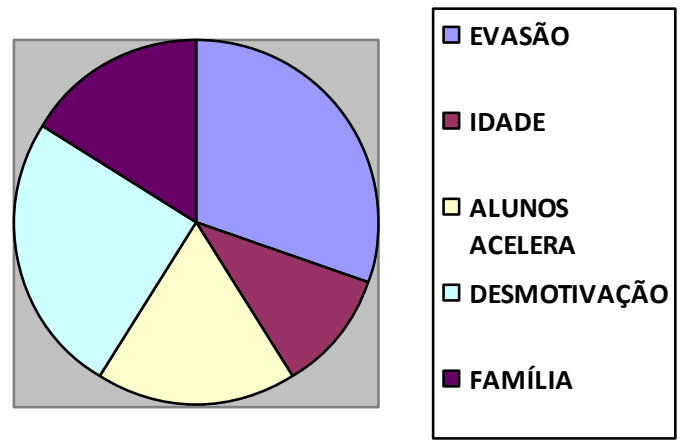

Principais problemas identificados

\begin{tabular}{|c|c|c|c|c|c|}
\hline Problemas & G & U & T & G x U x T & Prioridade \\
\hline Evasão & 4 & 5 & 4 & 80 & 2 \\
\hline Desmotivação & 5 & 4 & 4 & 80 & 2 \\
\hline Qualidade das Aulas & 5 & 4 & 4 & 80 & 2 \\
\hline $\begin{array}{c}\text { Utilização das Mídias } \\
\text { Tecnológicas }\end{array}$ & 5 & 4 & 5 & 100 & 1 \\
\hline
\end{tabular}




\section{Detalhamento do problema}
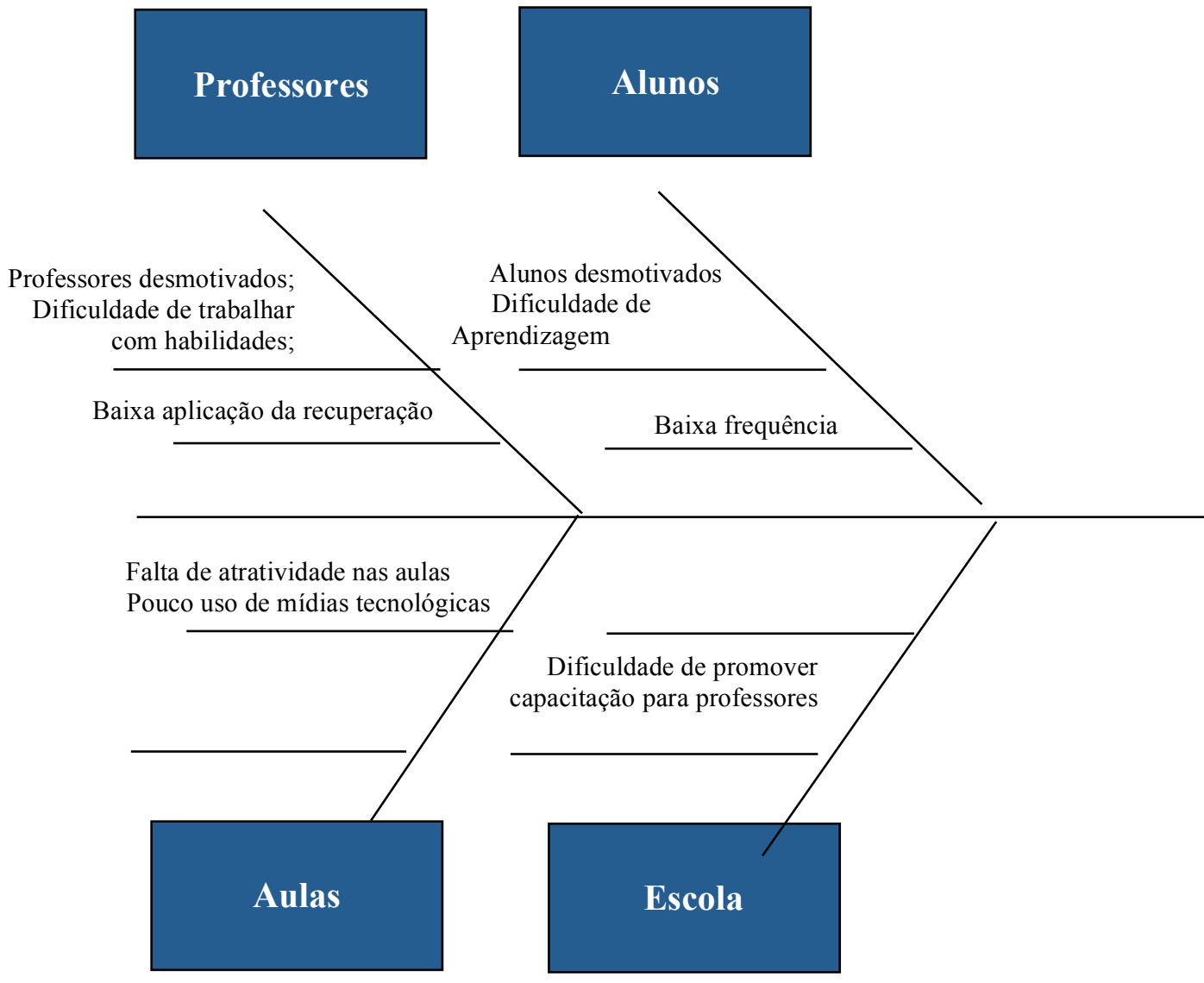
A partir das pesquisas realizadas pela equipe escolar e das discussões sobre o contexto da escola, foi desenvolvida a seguinte Matriz SWOT:

\begin{tabular}{|c|c|c|}
\hline & Aspectos favoráveis & Aspectos desfavoráveis \\
\hline & FORÇAS & FRAQUEZAS \\
\hline 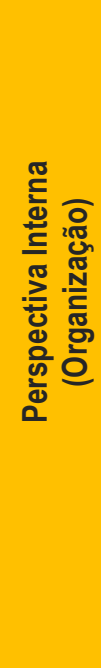 & $\begin{array}{l}\text { Laboratório de informática bem equipado e biblioteca } \\
\text { com um excelente acervo. } \\
\text { Bom entrosamento entre os alunos e a equipe } \\
\text { diretiva. } \\
\text { Entrosamento do corpo docente na execução das } \\
\text { tarefas / eventos, propostos pela unidade. } \\
\text { Estrutura física e espaço para desenvolvimento de } \\
\text { ações. } \\
\text { Implementação e execução das ações pedagógicas } \\
\text { por toda a comunidade escolar. }\end{array}$ & $\begin{array}{l}\text { Baixa auto estima por parte dos alunos. } \\
\text { Evasão em algumas turmas } \\
\text { Infrequência por parte dos professores. } \\
\text { Carência de funcionários de apoio na unidade para } \\
\text { dar conta da demanda. } \\
\text { Má conservação do laboratório de ciências, do } \\
\text { auditório e da quadra da unidade. }\end{array}$ \\
\hline \multirow[b]{2}{*}{ 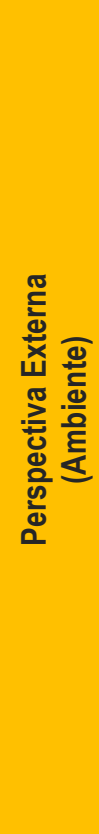 } & OPORTUNIDADES & AMEAÇAS \\
\hline & $\begin{array}{l}\text { Programa de Produção Cultural em Divulgação } \\
\text { Científica da Fundação Oswaldo Cruz. } \\
\text { Participações de cursos do PRONATEC. } \\
\text { Fábrica Verde de Capacitação Profissional de } \\
\text { Montagem e Manuntenção de Computadores. } \\
\text { Participação na Olimpíada Brasileira de Matemática } \\
\text { (OBMEP). }\end{array}$ & $\begin{array}{l}\text { Problemas com a queda de luz, devido ao furto de } \\
\text { energia da região. } \\
\text { Violência nas comunidade do entorno. } \\
\text { Problemas com a internet e com a telefonia devido ao } \\
\text { furto de cabos. } \\
\text { Grande evasão escolar no período entre outubro } \\
\text { dezembro devido as oportunidades de trabalhos } \\
\text { temporários. }\end{array}$ \\
\hline
\end{tabular}

Analisando a matriz, percebe-se que a escola conta com forças e oportunidades significativas para implementação de projetos e ações. As fraquezas são pontuais e devem ser trabalhadas ao longo do ano com ações por parte da Equipe Diretiva e Pedagógica. A evasão e a desmotivação dos alunos podem ser sanadas, como já foi citado antes, a partir de aulas atrativas e atividades diversificadas.

A escola necessita de um bom investimento na parte física. A ameaça que pode impactar na implementação de Projetos que visam a utilização de mídias são as constantes quedas de luz. Porém, o problema está sendo solucionado junto à Regional/ SEEDUC.

\section{Ações corretivas}


Visando preparar a organização para o desenvolvimento do projeto, no intuito combater as fraquezas e reduzir os possíveis impactos das ameaças, foram definidas as seguintes ações:

1. Promoção de reuniões pedagógicas para com a finalidade de trabalhar a Portaria 419 (Portaria de Normatização das Ações Pedagógicas) e sua implementação por parte dos professores.

2. Palestras bimestrais com os professores para a divulgação dos resultados das avaliações externas (SAERJINHO) e mecanismos de obtenção de bons resultados.

3.Implantação do uso do Banco de Itens por parte dos professores nas avaliações internas, a fim de chegar um bom resultado de ID e IF na unidade.

4. Implementação de salas de mídia para tornar as aulas atrativas e utilização de recursos tecnológicos/ pedagógicos.

5. Promoção de palestras motivacionais com os alunos sobre a importância da continuidade dos estudos e elevação da autoestima. Conscientização.

6. Elaboração e execução intensa de um plano de ação ambiental.

\section{Oportunidade identificada}

A proposta do Projeto visa tornar a escola e as aulas mais atrativas, através de ações por parte do Corpo Docente, da Equipe Pedagógica e da Direção. Dessa forma, a cada ação, é possível diminuir a evasão e a desmotivação dos alunos. Através das salas de mídia e da informatização de alguns espaços o aluno poderá se sentir protagonista do processo ensino-aprendizagem, motivado a aprender e com gosto pela escola. A implementação de salas de mídia irá contribuir efetivamente na prática do professor, pois no ensino médio, muitos alunos apresentam seminários, trabalhos, etc. Além disso, o professor poderá utilizar efetivamente 0 acervo de vídeos educativos da escola, acessar e trabalhar o banco de itens e os resultados das avaliações externas junto com seus alunos, de forma dinâmica e visual.

A escola realizará durante uma semana, com grupos de professores por turno, uma capacitação e workshops da utilização de mídias, fornecendo ao final um certificado de atualização. A ideia é convidar alguns profissionais de TI para palestrar sobre a utilização e o objetivo das mídias em sala de aula. As salas serão utilizadas com agendamento regular. $O$ ideal é conscientizar o professor que ele recorra aos espaços diversas vezes para realizar suas aulas, avaliações e também discutir os resultados com os alunos.

Além das ações do corpo docente, as salas serão utilizadas para encontros pedagógicos, reuniões, Conselhos de Classe e até atividades do Grêmio.

O objetivo é tornar a escola interativa com os alunos, onde os mesmos possam ter acesso nas salas de pesquisa à internet e até Wifi, além do laboratório de informática. Sabemos da grande dificuldade dos professores do uso do celular em sala de aula pelos alunos. Assim, identifica-se mais uma oportunidade de utilizar esse objeto pessoal como ferramenta de aprendizagem interagindo nas salas de mídia, onde 0 aluno poderá apresentar sua visão e se expressar.

\section{Detalhamento do produto/serviço elou processo}

\section{Foco do projeto}

Série ou conjunto de séries beneficiadas: $1^{\mathrm{a}}, 2^{\mathrm{a}}$ e $3^{\mathrm{a}}$ série do $\mathrm{E}$. Médio

Disciplina ou conjunto de disciplinas trabalhadas: Todas as Disciplinas

\section{Etapas do projeto}

O projeto será composto pelas seguintes etapas:

\section{Etapa 1 - ESTRUTURAÇÃO}

Objetivo: Implementar e estruturar os espaços favoráveis ao Projeto Olhar Digital.

Impacto na aprendizagem: Disponibilização de espaços motivadores de aprendizagem e atividades 
multimídias.

Atividades a serem realizadas:

\section{Atividade 1.1 - Gestão em ação: Estruturando as salas!}

Descrição: Nessa atividade, específica da Gestão, as salas serão estruturadas para se tornarem ambientes multimídias. Durante esse período, a equipe diretiva realizará ações de implementação, como pesquisa de orçamentos, a compra e instalação dos equipamentos necessários e a ambientação das salas (pintura, parte elétrica, climatização, etc). 0 projeto visa a montagem de no mínimo 3 salas de multimídia.

\section{Duração: 15/12/2014 até 10/03/2015}

Recursos necessários: Materiais para reforma das salas (tinta, tomadas, cortina), Ar-condicionado, Lousa interativa, Projetor, Quadro branco, Tela de projeção, Sistema de som, racks, estantes, persiana armários e mural de cortiça (tamanho médio).

Equipe envolvida: Direção e Profissionais de Informática.

\section{Etapa 2 - AMBIENTAÇÃO / INTERAÇÃO}

Objetivo: Introduzir o uso das mídias entre os docentes e discentes, estabelecendo a reflexão e a discussão, com vista a ampliar as práticas e despertar as possibilidades de utilização das ferramentas pedagógicas.

Impacto na aprendizagem: Motivação com as aulas interativas e o protagonismo, fazendo com que os alunos tenham oportunidade de interagir com as disciplinas de forma dinâmica, gerando como resultado a melhoria do processo ensino-aprendizagem.

Atividades a serem realizadas:

\section{Atividade 2.1 - Workshop Visitação e Ambientação: "T.I: Não é bicho de sete cabeças"}

Descrição: Após a estruturação das salas, será realizado um workshop de visitação, com rodízio de professores por disciplina, onde haverá capacitação com relação ao uso dos equipamentos e softwares com relação à especificidade das disciplinas e no geral. Ex.: Geografia (Mapas, fotos...), Matemática (Gráficos...), L. Portuguesa (Textos interativos...), Química (Tabela Periódica...), Artes (Produções artísticas, imagens...)

Duração: 15/03/2015 até 30/03/2015

Recursos necessários: Materiais gráficos (manuais/ apostilas)

Equipe envolvida: Direção, Coordenação Pedagógica, Profissionais de Informática e NTE/SEEDUC

\section{Atividade 2.2 - "Praticando o Olhar Digital"}

Descrição: Serão realizados encontros regulares de planejamento, para que os grupos de docentes possam elaborar ações pedagógicas e implementá-las nos planos de curso. Ao final do primeiro ano, a escola fará uma apresentação dos trabalhos das turmas. No término do segundo, haverá culminância das ações, que serão continuidade das anteriores e no qual os responsáveis e alguns profissionais da SEEDUC serão convidados. Será realizada uma Feira Tecnológica, com stands, onde os alunos poderão utilizar seus celulares e smartphones, além de equipamentos (computador, notebook, Datashow, tablets...), para expor seus seminários e trabalhos finais. Tais apresentações farão parte das avaliações de $3^{\circ}$ bimestre. Cada stand apresentará um trabalho orientado pelos professores, com bannner de divulgação dos componentes, Professores Orientadores e as principais ideias. Em uma das salas de mídia, haverá também uma atividade de aplicação do Banco de Itens, com questões das avaliações externas para que os alunos possam participar chamado "Sabatina Digital", que contará com a orientação de Professores de L. Portuguesa e Matemática. Os melhores trabalhos serão premiados.

Duração: 05/04/2015 até 05/12/2016

Recursos necessários: Salas de mídia, Materiais para exposição de trabalhos e logística (banners, aramados, 
tendas brancas, etc).

Equipe envolvida: Toda a comunidade escolar

\section{Novidade trazida pelo projeto}

O Projeto irá proporcionar aulas lúdicas e pedagógicas, permitindo a sinestesia entre o mundo concreto e 0 virtual. Possibilitará a utilização dos múltiplos recursos, conforme as necessidades, aumentando a interatividade, 0 interesse e a resposta dos alunos. Pessoa-chave no processo educacional, o professor, passa a contar com ferramentas que proporcionam interatividade baseada em recursos audiovisuais e de acesso à internet. $O$ resultado é o enriquecimento das dinâmicas em sala de aula e da forma de transmitir a informação ao aluno.

Além de favorecer às aulas atrativas, a utilização das mídias despertará no aluno o papel de protagonista do processo ensino-aprendizagem, fazendo com que o mesmo se empenhe nos projetos da escola e na própria Feira de Tecnologia, que será realizada a cada dois anos. A continuidade do Projeto tem como um dos objetivos reduzir a evasão, fazendo com que o discente se envolva cada vez mais no processo.

\section{Cronograma de execução}

\begin{tabular}{|c|c|c|c|c|c|c|c|c|c|c|c|c|c|}
\hline \multirow{2}{*}{\multicolumn{2}{|c|}{ Atividades }} & \multicolumn{4}{|c|}{2014} & \multicolumn{4}{|c|}{2015} & \multicolumn{4}{|c|}{2016} \\
\hline & & \multirow{2}{*}{$\begin{array}{l}\text { Jan- } \\
\text { Mar }\end{array}$} & \multirow{2}{*}{$\begin{array}{l}\text { Abr- } \\
\text { Jun }\end{array}$} & \multirow{2}{*}{$\begin{array}{l}\text { Jul- } \\
\text { Set }\end{array}$} & \multirow{2}{*}{$\begin{array}{l}\text { Out- } \\
\text { Dez }\end{array}$} & \multirow{2}{*}{$\begin{array}{l}\text { Jan- } \\
\text { Mar }\end{array}$} & \multirow{2}{*}{$\begin{array}{l}\text { Abr- } \\
\text { Jun }\end{array}$} & \multirow{2}{*}{$\begin{array}{l}\text { Jul- } \\
\text { Set }\end{array}$} & \multirow{2}{*}{$\begin{array}{l}\text { Out- } \\
\text { Dez }\end{array}$} & \multirow{2}{*}{$\begin{array}{l}\text { Jan- } \\
\text { Mar }\end{array}$} & \multirow{2}{*}{$\begin{array}{l}\text { Abr- } \\
\text { Jun }\end{array}$} & \multirow{2}{*}{$\begin{array}{l}\text { Jul- } \\
\text { Set }\end{array}$} & \multirow{2}{*}{$\begin{array}{l}\text { Out- } \\
\text { Dez }\end{array}$} \\
\hline Etapa 1 & Ativ. 1.1 & & & & & & & & & & & & \\
\hline \multirow{2}{*}{ Etapa 2} & Ativ. 2.1 & & & & & & & & & & & & \\
\hline & Ativ. 2.2 & & & & & & & & & & & & \\
\hline
\end{tabular}

\section{Gestão estratégica}

\section{Objetivos estratégicos}

\begin{tabular}{|c|c|c|c|}
\hline Objetivos & Metas & Indicadores & Acompanhamento \\
\hline \multirow{3}{*}{$\begin{array}{l}\text { Aumentar o nível } \\
\text { de interesse e } \\
\text { compreensão dos } \\
\text { alunos nas } \\
\text { diversas } \\
\text { disciplinas }\end{array}$} & $\begin{array}{c}\text { Aumentar o índice de } \\
\text { permanência na escola de } 81 \% \\
\text { para } 85 \% \text { até dezembro de } 2015 \text {. }\end{array}$ & $\begin{array}{l}\text { Frequência geral dos } \\
\text { alunos }\end{array}$ & $\begin{array}{l}\text { Controle da frequência quinzenal/ } \\
\text { bimestral e realização de reuniões de } \\
\text { responsáveis. }\end{array}$ \\
\hline & $\begin{array}{l}\text { Aumentar o índice de aprovação } \\
\text { do EM de } 52 \% \text { para } 60 \% \text { até } \\
\text { dezembro de } 2015 \text {. }\end{array}$ & $\begin{array}{l}\text { Práticas } \\
\text { Pedagógicas bem } \\
\text { sucedidas }\end{array}$ & $\begin{array}{l}\text { Registro das práticas bimestrais e } \\
\text { POPs. Compartilhamento das } \\
\text { práticas nas reuniões de } \\
\text { planejamento. }\end{array}$ \\
\hline & $\begin{array}{l}\text { Aumentar o IDERJ EM de 1,2 } \\
\text { para 4,0 até dezembro de } 2015\end{array}$ & $\begin{array}{l}\text { Atratividade das } \\
\quad \text { aulas }\end{array}$ & $\begin{array}{l}\text { Reunião com representantes de } \\
\text { turma. Acompanhamento dos } \\
\text { resultados de aprovação bimestral. }\end{array}$ \\
\hline
\end{tabular}




\begin{tabular}{|c|c|c|c|}
\hline & $\begin{array}{c}\text { Aumentar o índice de aprovação } \\
\text { sem progressão parcial de 37\% } \\
\text { para 43\% até dezembro de 2015 }\end{array}$ & $\begin{array}{c}\text { Aprovação sem } \\
\text { Progressão Parcial } \\
\text { (dependência) }\end{array}$ & $\begin{array}{c}\text { Acompanhamento através do mapão } \\
\text { de notas da turma nas disciplinas }\end{array}$ \\
\cline { 2 - 4 } $\begin{array}{c}\text { Aumentar a taxa } \\
\text { de desempenho } \\
\text { nos resultados das } \\
\text { avaliações } \\
\text { internas e externas }\end{array}$ & $\begin{array}{c}\text { Aumentar o desempenho no } \\
\text { SAERJ (ID) no EM de 2,3 para } \\
3,9 \text { até dezembro de 2015 }\end{array}$ & $\begin{array}{c}\text { Desempenho nas } \\
\text { Avaliações Externas }\end{array}$ & $\begin{array}{c}\text { Utilização do banco de itens pelos } \\
\text { professores e registro dos resultados. } \\
\text { Realização de simulados e correção } \\
\text { pelos professores. }\end{array}$ \\
\cline { 2 - 5 } & $\begin{array}{c}\text { Aumentar o índice de adequação } \\
\text { idade/ série de 55\% para 62\% até } \\
\text { dezembro de 2015. }\end{array}$ & $\begin{array}{c}\text { Adequação Idade- } \\
\text { Série }\end{array}$ & $\begin{array}{c}\text { Realizar levantamentos da idade- } \\
\text { série durante matrícula inicial e } \\
\text { matrícula final. Vincular com os } \\
\text { resultados de aprovação }\end{array}$ \\
\hline $\begin{array}{c}\text { Aumentar a } \\
\text { participação dos } \\
\text { alunos nos } \\
\text { projetos e feiras } \\
\text { pedagógicas }\end{array}$ & $\begin{array}{c}\text { Aumentar o índice de } \\
\text { permanência na escola de } 81 \%\end{array}$ & $\begin{array}{c}\text { Frequência geral dos } \\
\text { alunos }\end{array}$ & $\begin{array}{c}\text { Controle da frequência quinzenal/ } \\
\text { bimestral e realização de projetos } \\
\text { interativos. }\end{array}$ \\
\hline
\end{tabular}

\section{Continuidade do projeto}

O próprio projeto possui características de continuidade, pois a Feira de Tecnologia pode acontecer a cada dois anos. Porém, o importante é não deixar que as salas de mídia fiquem sem utilização por parte dos professores. $O$ ideal é a Equipe Diretiva estar sempre acompanhando a manutenção dos equipamentos e junto com a Equipe Pedagógica, implementar ações de continuidade com objetivo de melhorias no ensinoaprendizagem. Além disso, é importante a adequação do projeto ao PPP da escola.

\section{Marketing e comunicação}

\section{Lançamento do projeto}

O projeto será lançado na semana de planejamento que antecede o início das aulas, no começo do ano letivo de 2015 , onde haverá divulgação das propostas nas reuniões pedagógicas, com a utilização de slides em data show. A escola também providenciará um informativo através dos e-mails dos professores. Durante essa semana, as ações estarão voltadas para o PPP da escola junto com o Projeto Espaço Olhar Digital. Os professores serão orientados a planejar suas atividades anuais conforme o Currículo Mínimo e adequar as ações ao Projeto da escola. A Coordenação Pedagógica e a Equipe Diretiva estarão à frente dessas etapas.

No que diz respeito à divulgação com a comunidade escolar, serão dispostos pelos espaços da unidade, diversos banners (feitos em gráfica) com o título "Chamada Virtual: participe do Olhar Digital!" na primeira semana de aula. Na semana posterior, a Coordenação Pedagógica, os representantes de turma e o grêmio escolar visitarão as salas, propagando o projeto. A ideia é que todos participem do Projeto, pois o mesmo estará inserido automaticamente nas ações pedagógicas, no currículo escolar e fará parte das avaliações. Além disso a Direção irá também divulgar a premiação para as melhores turmas.

\section{Canais de comunicação e acompanhamento do projeto}




\section{Marketing interno}

Serão utilizados cartazes e um blog informativo, onde a comunidade poderá fazer comentários e sugestões. A escola contará com grupos de professores de disciplinas variadas, serão chamados os "Grupos Foco". Cada grupo focará uma ação do projeto e estarão divididos da seguinte forma: Ações Criativas, Executores, Monitores, Relações, Suporte Tecnológico, Dinamizadores, Colaboradores, Grêmio. Todos serão formados por professores, membros da Equipe Pedagógica, da Direção e alunos. A cada quinzena, haverá encontros para discussão do projeto e planejamento das ações, que serão realizados nas próprias salas de mídia. Ao final do encontro, haverá lanche e os grupos formalizarão as ações. Cada Grupo Foco desempenhará uma função: Ações Criativas ficará responsável pela elaboração/ execução de atividades atrativas para as salas de mídia, envolvendo o pedagógico e a comunidade escolar; Executores realizarão integralmente as ações, colocando em prática o planejamento; Monitores apontarão as falhas a serem corrigidas e as ações bem sucedidas e também irão auxiliar na execução; o Grupo Relações terá a incumbência de propagar as ações e pesquisar seus resultados junto à comunidade escolar através do blog e também auxiliará a Direção no Marketing Externo; o Suporte Tecnológico será formado por professores que dominam a TI, colaboradores e técnico de informática, estes estrão envolvidos com toda parte de software e equipamentos; os Dinamizadores promoverão encontros, dinâmicas e reuniões com os grupos e a comunidade; os Colaboradores estarão inseridos no contexto geral, dando apoio às ações, será composto por membros dos diversos segmentos da escola; e finalizando, o Grêmio que ficará responsável pela mobilização entre os alunos, na participação do projeto e na criação de uma fanpage, com acompanhamento de professores e Coordenação Pedagógica.

\section{Marketing externo}

Os canais externos a serem utilizados serão um blog (comunidade escolar), a fanpage (Grêmio, Professores e Equipe Pedagógica), e-mails (mala direta), grupo no whatsapp (entre o corpo docente e a Equipe Pedagógica) e 0 aplicativo Google Drive para pesquisa (comunidade escolar). Essas ferramentas serão usadas com regularidade a cada semana e ao longo do projeto. Como o projeto envolve tecnologia, nada mais coerente do que utilizar a mesma.

\section{Parceiros estratégicos}

$\checkmark$ Corpo Docente: C. E. Professor Clóvis Monteiro

$\checkmark$ NTE (Núcleo de Tecnologia): SEEDUC

$\checkmark$ Técnico de Informática: serviços contratados / Técnico de Manutenção: serviços contratados

$\checkmark$ SESI/FIRJAN

O Corpo Docente irá contribuir no sentido da atuação dos Grupos Focos e da realização das ações pedagógicas direcionadas à proposta. O Núcleo de Tecnologia (NTE) estará envolvido com as orientações no que diz respeito aos equipamentos e uso pedagógico dos mesmos e também participarão como dinamizadores dos workshops e reuniões. $O$ técnico de informática cuidará da instalação dos equipamentos e da estrutura das salas juntamente com o técnico de manutenção. A instituição SESI/FIRJAN oferecerá cursos de extensão com plataforma on line para os professores.

A escola tem a oferecer espaço para capacitações, workshops, reuniões, eventos, etc. Para os técnicos haverá oportunidade para divulgação dos seus cursos profissionalizantes junto aos alunos e a utilização frequente dos serviços pela unidade. Para adesão dos parceiros será realizada uma reunião com um bom café da manhã e convite aos eventos.

\section{Divulgação de resultados}

$\checkmark$ Reuniões com coffeebreak e utilização de projetores para demonstrar os resultados.

$\checkmark$ Apresentações dos trabalhos dos alunos. O próprio corpo discente irá apresentar seu trabalho diante de professores e parceiros 
$\checkmark$ Seminários de professores relatando os resultados

$\checkmark$ Reuniões com os Grupos Foco

\section{Equipe do projeto}

\section{Equipe interna}

\begin{tabular}{|c|c|c|c|c|}
\hline Cargo & Formação & $\begin{array}{l}\text { Tempo na } \\
\text { escola }\end{array}$ & Experiência anterior & $\begin{array}{c}\text { Responsável } \\
\text { pelas atividades: }\end{array}$ \\
\hline Dir. Geral & $\begin{array}{c}\text { Gestão Empreendedora } \\
\text { História }\end{array}$ & 1 ano & $\begin{array}{c}\text { Dir. Adjunta } \\
\text { Administrativo e Finanças }\end{array}$ & Kátia Souza \\
\hline Dir. Adjunta & $\begin{array}{c}\text { Gestão Empreendedora } \\
\text { Artes }\end{array}$ & 1 ano & $\begin{array}{c}\text { Dir. Adjunta } \\
\text { Pedagógica e Tesoureira }\end{array}$ & Graziela Moreira \\
\hline Coord. Pedagógica & $\begin{array}{l}\text { Matemática } \\
\text { Pedagogia }\end{array}$ & 4 meses & $\begin{array}{l}\text { Coord. Pedagógica } \\
\text { Ações Pedagógicas }\end{array}$ & Elizabete \\
\hline Coord. Pedagógica & L. Portuguesa & 7 meses & $\begin{array}{c}\text { Professora } \\
\text { Ações Pedagógicas e } \\
\text { Mobilização }\end{array}$ & Evanilda \\
\hline $\begin{array}{l}\text { Orientação } \\
\text { Educacional }\end{array}$ & $\begin{array}{l}\text { Sociologia } \\
\text { Geografia } \\
\text { Pedagogia }\end{array}$ & 1 ano & $\begin{array}{c}\text { Orientação Educacional } \\
\text { Atuação direta com o corpo } \\
\text { discente }\end{array}$ & Janaína \\
\hline
\end{tabular}

\section{Profissionais externos}

\begin{tabular}{|c|c|c|}
\hline Tipo de profissional & Competências necessárias & Participação no projeto \\
\hline Técnico de Manutenção & Reforma / Estruturação e Manutenção & $\begin{array}{c}\text { Análise, reforma e estruturação das } \\
\text { salas }\end{array}$ \\
\hline Técnico de Informática & Instalação/ Manutenção & $\begin{array}{c}\text { Análise, estruturação das salas, } \\
\text { instalação de hardwares, softwares, } \\
\text { mobiliário e equipamentos }\end{array}$ \\
\hline
\end{tabular}

\section{Plano financeiro}

\section{Investimentos (despesas de capital)}

\begin{tabular}{|c|c|c|c|}
\hline Obras e infraestrutura & Ano 1 & Ano 2 & Ano 3 \\
\hline Pintura e pequenas reformas & $2.000,00$ & 700,00 & 200,00 \\
\hline Climatização & $4.000,00$ & $2.000,00$ & 999,90 \\
\hline Elétrica & $3.000,00$ & $4.000,00$ & $1.000,00$ \\
\hline Mobiliário & $9.000,00$ & $2,000,00$ & 500,00 \\
\hline Total & $\mathbf{1 8 . 0 0 0 , 0 0}$ & $\mathbf{8 . 7 0 0 , 0 0}$ & $\mathbf{2 . 6 9 9 , 9 0}$ \\
\hline
\end{tabular}

\begin{tabular}{|c|c|c|c|}
\hline Material permanente & Ano 1 & Ano 2 & Ano 3 \\
\hline Computadores & $2.697,00$ & 500,00 & 100,00 \\
\hline Data show & $5.127,30$ & 0 & 0 \\
\hline Lousa Digital & $13.500,00$ & 0 & 0 \\
\hline Modem/ Roteadores (wifi) & 329,70 & 110,90 & 0 \\
\hline Impressoras & 606,00 & 202,00 & 0 \\
\hline TV / DVD & $1.181,00$ & 500,00 & $\mathbf{1 0 0 , 0 0}$ \\
\hline Total & $\mathbf{2 3 . 4 4 1 , 0 0}$ & $\mathbf{8 1 2 , 9 0}$ & \\
\hline
\end{tabular}




\section{Despesas correntes}

\begin{tabular}{|c|c|c|c|}
\hline Material de consumo & Ano 1 & Ano 2 & Ano 3 \\
\hline Galão de Tinta & 897,00 & 300,00 & 100,00 \\
\hline $\begin{array}{c}\text { Pequenos equipamentos } \\
\text { (estabilizadores, etc) }\end{array}$ & $1.000,00$ & 500,00 & 200,00 \\
\hline Resmas de papel A4 & 139,00 & 417,00 & 417,00 \\
\hline Toner (cartuchos) & 144,00 & $1.152,00$ & $1.152,00$ \\
\hline Total & $\mathbf{2 . 1 8 0 , 0 0}$ & $\mathbf{2 . 3 6 9 , 0 0}$ & $\mathbf{1 . 8 6 9 , 0 0}$ \\
\hline
\end{tabular}

\begin{tabular}{|c|c|c|c|}
\hline Gastos com locomoção & Ano 1 & Ano 2 & Ano 3 \\
\hline Gasolina & 300,00 & 300,00 & 200,00 \\
\hline Total & 600,00 & 600,00 & 600,00 \\
\hline
\end{tabular}

\begin{tabular}{|c|c|c|c|}
\hline Serviços de terceiros & Ano 1 & Ano 2 & Ano 3 \\
\hline Manutenção das salas & 1000,00 & 1000,00 & 1000,00 \\
\hline Manutenção dos Equipamentos & 1000,00 & 1000,00 & 1000,00 \\
\hline Total & $\mathbf{2 0 0 0 , 0 0}$ & $\mathbf{2 0 0 0 , 0 0}$ & $\mathbf{2 0 0 0 , 0 0}$ \\
\hline
\end{tabular}

\section{Recursos do edital}

\begin{tabular}{|c|c|c|c|c|}
\hline Tipo de item & Ano 1 & Ano 2 & Ano 3 & Total \\
\hline Despesas de Capital & $41.441,00$ & $9.512,90$ & $2.799,90$ & $53.752,90$ \\
\hline Obras e infraestrutura & $18.000,00$ & $8.700,00$ & $2.699,90$ & $29.399,00$ \\
\hline Material permanente & $23.441,00$ & 812,90 & 100,00 & $24.353,90$ \\
\hline Despesas Correntes & $4.480,00$ & $4.669,00$ & 4469,00 & $14.218,00$ \\
\hline Material de consumo & $2.180,00$ & $2.369,00$ & $1.869,00$ & $6.418,00$ \\
\hline Gastos com locomoção & 300,00 & 300,00 & 200,00 & $1.800,00$ \\
\hline Serviços de terceiros & $2.000,00$ & $2.000,00$ & $2.000,00$ & $6.000,00$ \\
\hline Total do projeto & $45.921,00$ & $14.181,90$ & $4.069,00$ & $67.970,90$ \\
\hline
\end{tabular}

\section{Contrapartida}

\begin{tabular}{|c|c|c|c|}
\hline Profissionais & $\begin{array}{c}\text { Horas dedicadas ao } \\
\text { projeto }\end{array}$ & Valor médio/hora & $\begin{array}{c}\text { Contrapartida por } \\
\text { profissional }\end{array}$ \\
\hline Professor 1 & 60 & 16,10 & 966,00 \\
\hline Técnico de informática & 100 & 16,10 & 1610,00 \\
\hline Professor 2 & 60 & 16,10 & 966,00 \\
\hline Professor 3 & 60 & 16,10 & 966,00 \\
\hline & & & \\
\hline & & & \\
\hline Total de contrapartida & $\mathbf{2 8 0}$ & - & $\mathbf{4 . 5 0 8 , 0 0}$ \\
\hline
\end{tabular}

